\title{
Athetosis in Typhoid Fever
}

\author{
Major J W Simon,* \\ MA(Oxon), MRCP(UK), DTM\&H, RAMC \\ Senior Specialist in Medicine, British Military Hospital, Dharan
}

SUMMARY: A case of typhoid fever with neuropsychiatric features is described. These comprised confusion and de- $\overrightarrow{\vec{F}}$ lirium, meningism, a single major convulsion and bilateral athetoic movements. Athetosis has not previously been de- $\stackrel{\mathscr{D}}{O}$ scribed in typhoid fever and must now be added to the long list of neuropsychiatric manifestations of this disease.

\section{Case Report}

A 20 year old Nepalese male was admitted to the British Military Hospital, Dharan in South East Nepal with a one week history of fever. The day before admission he had a rigor. On examination he was toxic and dehydrated but well nourished. He was delirious, confused and incontinent of faeces and urine. The temperature was $39.5^{\circ} \mathrm{C}$, the blood pressure $110 / 70 \mathrm{~mm}$ $\mathrm{Hg}$. and the pulse 100 per minute. The spleen was palpable $2 \mathrm{cms}$ below the left costal margin and the abdomen was distended. There was marked neck stiffness but Kernig's sign was negative. He showed persistent bilateral classical athetoic movements. Neurological examination was otherwise normal and in particular there were no choreiform or myoclonic movements or evidence of Parkinsonism.

Investigations showed a white cell count of $3.4 \times 10^{9} / 1$ with 60 per cent lymphocytes. The plasma sodium was $126 \mathrm{mmol} / 1$ but urea and potassium were normal. Salmonella typhi was isolated in pure growth from three blood cultures. Urinalysis showed a trace of protein. The cerebrospinal fluid (CSF) showed a normal glucose but the protein was mildly elevated to $52 \mathrm{mg} / \mathrm{dl}$ and there were two white cells $/ \mathrm{mm}^{3}$. A direct Gram stain failed to reveal any organisms and the CSF was culture negative.

$\mathrm{Hb}$, platelet count, liver function tests, a Chest X-ray and electrocardiogram were all normal. Repeated examinations of the peripheral blood for malarial parasites were negative. Japanese encephalitis viral antibody titres were negative.

Immediately after admission he was started on chloramphenicol $1 \mathrm{~g}$ six hourly intravenously and rehydrated with intravenous normal saline. Twelve hours after admission he suffered a single generalised convulsion controlled by intravenous diazepam. Twenty four hours after admission his athetoic movements had ceased. Thirty six hours after admission he was apyrexial and lucent. He subsequently made a rapid uneventful and complete recovery.

\section{Discussion}

This patient, a proven case of typhoid, showed certain neuropsychiatric features. He was confused and delirious, had meningism, suffered a major convulsion

*now Senior Specialist in Medicine, British Military Hospital, Hong Kong, BFPO 1.

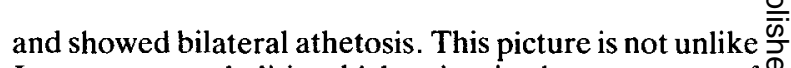

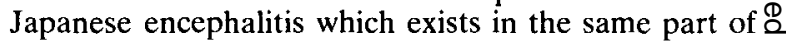
Nepal and the distinction between these two entities has $\infty$ recently been discussed by Henderson et al., in this $\vec{\circ}$ journal ${ }^{\text {. }}$.

Neuropsychiatric manifestations are common in $\overrightarrow{\vec{\omega}}$ typhoid fever ${ }^{2}$. They were present in 50.4 per cent of a series comprising 246 patients from India ${ }^{3}$ and in over $57 \stackrel{\mathbb{Q}}{\vec{D}}$ per cent of a series of 959 patients in Nigeria ${ }^{4}$. A confusional or delirious state is the commonest $\vec{\omega}$ manifestation occurring in 25 to 50 per cent of all cases $\stackrel{\omega}{N}$ of typhoid. Meningism occurs in 5 per cent of cases but a true typhoid meningitis is rare. Convulsions vary incidence and occur in 2 to 10 per cent of cases $^{3,4}$. Othe manifestations are less common and include semi-coma, coma, generalised myoclonus, polyneuropath mononeuropathy, focal neurological deficits, spasticit $\$$ hypotonicity, tremor and basal ganglia disorder? Psychiatric manifestations include temporary amnesia schizophrenia and rarely hypomania. Basal gangli disorders are well described - a transient Parkinson 85 syndrome is seen in about 2 per cent of $\operatorname{cases}^{3,4}$ whis choreiform movements are well described in childre with typhoid ${ }^{5.6}$. A literature search suggests howeve that athetosis has not previously been reported.

This patient showed persistent bilateral athetoic movements which lasted a full 24 hours and then ceased. $\stackrel{\mathbb{Q}}{\square}$

This report adds athetoic movements, occurring as a $\overrightarrow{\vec{P}}$ transient and completely reversible phenomenon, to the $\stackrel{3}{\exists}$ long list of neuropsychiatric manifestations of typhoid fever.

\section{REFERENCES}

1 Henderson A Knight RJ and Livesey RJ. Typhoid masquerading as Japaneses encephalitis. JR Army Medz Corps 1984; 130: 183-184.

2 Christie AB. In: Infectious diseases epidemiology and clinical practice. 3rd ed. Churchill Livingstone, London? $1980 ; 47-102$.

3 Khosla SN, SRIVAStava SC and Gupta $S .3$ Neuropschiatric manifestations of typhoid. I Trop Med Hyg 1977; 80: 95-98.

4 OsunTOKUN BO et al. Neuropsychiatric manifestations of typhoid fever in 959 patients. Arch Neurol 1972; 27: $7-13$.

5 Pohowalla JN and Ghai JOP. Typhoid encephalo pathy in children. Indian J Paediatr 1957; 24: 137-142. N

6 SOOD SL and TANEJA PN. Typhoid fever: clinical picture and diagnosis. Indian J Child Health 1961; 10: 69-76. 